\title{
MACRO-PUBLIC RELATIONS: CRISIS COMMUNICATION IN THE AGE OF INTERNET
}

\author{
Zhongxuan Lin \\ University of Macau \\ Room PLG116, Faculty of Social Sciences \& Humanities, University of Macau, \\ Av. Padre Tomas Pereira, Taipa, Macao \\ lzhongx55@gmail.com \\ Yujuan Guo \\ Hong Kong Polytechnic University \\ Room 444 4/F, Kowloon Tong Campus of Polytechnic University, \\ 30 Renfrew Rd, Kowloon Tong, HK \\ alicegyj69100@gmail.com \\ Yingying Chen \\ 21st Century Business Herald \\ RM9, 11/F, Fung Yi Court, United Building, 3 Wu Kwong Street, \\ Hung Hom KLN, HK \\ kellycyymm@gmail.com
}

\begin{abstract}
In order to study the crisis communication in the age of Internet, the study takes the battle between two Internet companies, Tencent and Qihoo, as a case study, but focuses more on their huge public audiences, which may be defined as a "macro-public" crowd. The study employs multiple research methods including survey, focus groups interviews and content analysis to explore their "macro-public relations" which may be driven by the spiral of silence and crowd psychology. This dynamic underground power is the reason that two companies employed similar public relations strategies in crisis communication but the results of the crisis were different. The study attempts to contribute to the knowledge base by defining and highlighting the power and function of "macro-public relations" for
\end{abstract}


crisis communication in the age of Internet.

Keywords: Crisis Communication, Crowd Psychology, Internet, Public Relations, Spiral of Silence

\section{INTRODUCTION}

Crisis communication is one of the key themes of Public Relations (PR). Actually, most public relations programs are developed either to prevent a crisis or to recover from a crisis (Fearn-Banks, 2001). There have been many studies about public relations as a vital means of crisis communication; meanwhile, more and more studies pay attention to the crisis communication in the age of the Internet, echoing to the new challenges and opportunities posed by the rapid development of the new communication technologies. Following this lead, the study explores the specific crisis communication and outcome measurement of two grant Internet companies, but is more focused on the function of the underground power of their huge public audience.

The case of the battle between these two Internet companies, Tencent QQ and Qihoo 360 , will be mainly employed throughout the study. The crisis alleged to be so-called unfair business competition happened between Tencent, the most popular free instant messaging tool in Mainland China, and Qihoo, China's biggest antivirus service provider; they once belonged to and dominated China's different Internet segmented-markets, the instant messaging market and antivirus service market, respectively. In February 2010, Tencent began to promote its antivirus software, Tencent QQ Doctor, which received $40 \%$ of antivirus software's market share. Many functions of QQ Doctor were the same as those in Qihoo's antivirus software. The fight began when Qihoo accused Tencent of letting its software scan its users' computers for personal data, and issued tools to block Tencent's QQ components. The competition between two companies became the main reason causing the conflict, which developed into a crisis afterwards. The crisis, to some extent, belongs to the combination of confrontation and malevolence crisis. In addition, in the process of handling the crisis, the management of two companies presents characteristics of skewed value and misconduct. The most significant characteristic of the crisis is the public involvement, with the behaviors and variation of the public in this crisis, which makes this case distinct and thought provoking. 
Tencent is the world's largest online community, with about 712 million active QQ user accounts, while the Qihoo antivirus software has 378 million users. These numbers are much larger than most countries' populations. That means, once the companies made the competition public and involved their users' interests, and even competed at the expense of their users' interests, it was not only a business competition, but a disastrous crisis with an enormous population.

Such an enormous population in the backdrop of an electronic environment is a new collective or new public, which is different from the "segmented-stakeholders". In a sense, "segmented-stakeholders" are some type of "micro-public", while this new collective or new public is a kind of "macro-public". Besides the characteristics and behaviors of the "micro-public" when they act as an individual, the "macro-public" are more likely to assemble and act as a crowd, especially in the electronic environment, like the netizens in this case: they connect their own opinion with the macro-public opinions according to the spiral of silence, an "integrated model of opinions formation and change" (Noelle-Neumann, 1974, p.117), which is positive for them to form as a crowd. Then they are not just "micro-public" individuals, but a "macro-public" crowd, with "Several of the special characteristics of crowds such as impulsivity, irritability, incapacity to reason, absence of judgment or critical spirit, exaggeration of emotions and more besides are also observed amidst lower forms of evolution such as the savage and the child (Le Bon, 1982, p.23)."

Targeting this "macro-public" crowd, the study employed multiple research methods including surveys, focus group interviews and content analyses to explore their "macro-public relations," which may be driven by the spiral of silence and the crowd psychology. This dynamic underground power of "macro-public relations" is the reason why although the two companies employed similar PR strategies in crisis communication, the results of the crisis were different, with Qihoo gaining more support from the public. The study attempted to contribute to the knowledge base by defining and highlighting the power and function of "macro-public relations" as crisis communication in the electronic backdrop.

\section{THEORETICAL BACKGROUND}

Since the term "public relations" was coined early in the 20th century, the profession has been crisis driven, and most public relations programs are developed either to prevent a crisis or to recover from a crisis (Fearn-Banks, 2001). As Fink indicated, a crisis is a 
"turning point", "characterized by a certain degree of risk and uncertainty" (Fink, 1986, p.15), but not necessarily laden with irreparable negativity or absolute doom. That is the value of PR--minimizing damage to the organization in a crisis.

Crisis communication and PR theorists have found that organizations with specific practices tend to suffer less financial and reputational damage than do organizations without them (Fearn-Banks, 2001). These PR practices are built largely on the excellence theory of public relations credited primarily to Grunig and Grunig (1992), which is based on four PR models: press agentry model, public information model, two-way asymmetrical model, and two-way symmetrical model, from least desirable to most desirable in public relations practices. This theory is further developed by Fearn-Banks (1996) and Grunig and Repper (1992).

Other studies following this line have also been concerned with the relationship between the organization and its stakeholders, and more focused on the "increased relationships with intervening stakeholder groups" and "increased collaboration among stakeholders" (Mitroff \& Pearson, 1993, p.114).

These classical models and theories make a great contribution to the development of professional PR practices, which is also crucial for an organization to prevent a crisis, or suffer less and recover more rapidly from a crisis. Under this theoretical direction, organizations seem to be encouraged to segment the "public" into more specific "stakeholders" or target audiences, like the consumers, investors, media etc., rank them according to importance, and strive to develop and maintain strong relationships with them. In other words, "public relationship" seems to be segmented into a "segmented-stakeholders relationship". This trend of segmentation seems to fit quite well with the development of the PR industry, as well as society, in the past.

But since the advent of the Internet, this trend and its background theoretical frame have disclosed some limitations. Drawn from the situational theory of public, which is grounded in a systems perspective of public relations, some researchers have argued that on-line communicative interactions can result in the formation of new collectivities (Grunig \& Repper, 1992). Such collectivities mean new publics, representing new challenges of identification and analysis for public relations theorists and practitioners (Cozier \& Witmer, 2001).

Although Gordon (1997) noted that the term "public" is "common to all definitions" of the practice of public relations, it is still one of the most ambiguous concepts in the field's vocabulary, and the perspectives for research on a public range from mass and 
situational views to more recent approaches such as the agenda-building and "homo narrans" view (Vasquez \& Taylor, 2001). The new public in the electronic environment seems to penetrate all four of these perspectives of the public because of its natural characteristics. But when the rapid development of the Internet and the soaring growth of netizens are taken into consideration, the new public seems to connect more closely with the mass perspective which draws primarily from the works of Allport (1937), Blumer (1948), Herbst (1993), Lippmann (1922), and Price (1992), regarding a public as a single population of aggregate individuals with enduring characteristics (Vasquez \& Taylor, 2001).

Once having referred to the mass perspective, Crowd Psychology would be one of the inevitable resources for reference. Since Le Bon's major work The Crowd: A Study of the Popular Mind was first published in 1895, Gordon Allport described it as the most widely read psychology book of all time, in which Le Bon sums up the characteristics of the crowd psychology in a single flourish: "Several of the special characteristics of crowds such as impulsivity, irritability, incapacity to reason, absence of judgment or critical spirit, exaggeration of emotions and more besides are also observed amidst lower forms of evolution such as the savage and the child (Le Bon, 1982, p.23)." Obviously, this type of new public as mass or crowds is quite different from the carefully segmented stakeholders who are identified through research and ranked according to importance. Even though this classic crowd psychology has come under increasing attack in the past, the advent of the Internet and its collectives offers a new dawn for it (McPhail, 1991; Turner \& Killian, 1987).

Based on the above literature review, we find that there have been a number of researchers and theorists working on the PR models and theories, as well as the crisis communication and management, making great contributions to the academic theory the industry practices. However, these theories and practices are more focused on the "segmented-stakeholders relationship" in a micro-perspective, rather than a macro-perspective on the crowd of these "segmented-stakeholders", which would become a limitation in an electronic environment or a "cybercrisis" (Middleberg, 1996), where the unregulated on-line individuals and organizations are more easily assembled as a crowd. That may be influenced by not only the crowd psychology, but also the spiral of silence, an "integrated model of opinion formation and change (Noelle-Neumann, 1974, p.117)." Individuals holding a minority opinion will be compelled to conform to the opinion held by the majority or else will remain silent to avoid social isolation (Glynn \& McLeod, 1985; 
Salmon \& Kline, 1985); therefore, the spiral of silence seems to be positive for the formation of a crowd, as well as the new public for PR. These findings remind us to rethink and reexamine the "micro-public" in a macro-perspective to find out about the "macro-public," who are influenced by the spiral of silence and the crowd psychology.

\section{RESEARCH METHOD AND DATA COLLECTION}

Targeting this "macro-public" crowd, the study employed multiple research methods including surveys, focus group interviews and content analyses to explore their "macro-public relations," which may be driven by the spiral of silence and crowd psychology.

\section{Survey}

Surveys are excellent vehicles for measuring attitudes and orientation in a large population. This research method was firstly employed in our study, helping us understand individual attitudes and opinions toward this crisis and its impacts. We used an anonymous online questionnaire survey website, sojump (namely, the questionnaires star), which is one of the most famous professional online questionnaire survey websites in China, to receive first-hand data from the respondents. The participants are promised confidentiality and that the data are only used research.

The sample of the survey was made up of 71 participants, randomly selected from the public, who have a brief understanding of the whole crisis. They were invited to accomplish an online questionnaire in the Appendix A. The entire collection process lasted for three weeks. To assure the universality and representativeness, the respondents in this research were distributed among nearly 28 provinces in mainland China. All information was recorded, and lastly we obtained 71 pieces of valid results, which made up the final data to be analyzed.

\section{Focus Groups Interview}

Apart from collecting data from a survey which provided the general attitude of the public, we also employed the method of focus group which aims at exploring the variation trend of public's attitude in depth.

The participants of the focus group were mainland master students majoring in Corporate Communication, the Chinese University of Hong Kong. When taking the interview, they had been studying Corporate Communication for almost one year. 
Moreover, all of them paid a great deal of attention to the crisis. In this regard, this feature guarantees that all the subjects were able to provide their own professional opinions of the crisis.

The main questions for discussion are illustrated in Appendix B. The participants are required to answer the given questions and have in-depth discussion. During this process, all information from participants was recorded, and lastly we obtained three pieces of results, which make up the final data to be analyzed.

\section{Content Analysis}

Content analysis would be employed to study the media's and neitzens' attitudes, both traditional and new media, latent and manifest content would be analyzed to offer a more systematic and comprehensive view on this case.

By using the database wisenews, the biggest one in terms of Chinese news publication in Greater China, articles published in the Greater China's newspapers and magazines from 25th February 2010 to 4th November 2010 about "Tencent and Qihoo" in the text were identified and categorized for further content analysis. 2990 pieces of articles were collected during this period. A multistage sampling method was employed to select samples from these articles: Stage 1 - Selection of dates. Every article was analyzed from February 25th to July26th, since the issue has not drawn public attention, and article volume was not big. From July 27th to December4th, news appeared in various newspapers every day. Choosing dates of significant appearing news on the battle as anchor points, we analyzed news which happened one day before and after the publishing of news; Stage 2 - Selection of news. Five pieces of news were selected randomly from articles which appeared on those days for further analysis. These articles were classified under following criteria: post time of the article, general attitude of the articles, and evaluation of Tencent and Qihoo. For each article, we rated how positively or negatively it is shown. $5=$ highly positive, $4=$ positive, $3=$ neutral, $2=$ negative, $1=$ highly negative, 0 $=$ ambiguous.

As for analysis of netizens attitudes, the sample frame consists of comments appearing between 1st September 2010 to 5th November 2010 in the following media types: Sina micro blog, a platform which aroused most discussions on the case, and Tianya Community, one of the most popular and influential community website in Mainland China. 
Comments which appeared from 1st September 2010 to 5th November 2010 about "Tencent and Qihoo" in the text were identified and categorized for further content analysis. We used the same sampling method as that used in the content analysis of the media's attitude. Dates of appearing significant news were selected to make content analysis. 10 comments were randomly chosen for each day's analysis. Comments were divided into three categories: Support Tencent, Support Qihoo and Neutral.

\section{RESULT AND ANALYSIS}

\section{Outcome of the Survey}

Results of the survey show that Qihoo wins more supporters in the battle. Specifically, $25.4 \%$ of the respondents regard Qihoo as the winner while only $7 \%$ take Tencent as the winner. For aspects of PR strategy, crisis communication and media application, Qihoo gains more support than Tencent. Though the two parties took similar strategies, the results were different. $52.1 \%$ of participants made negative comments regarding Tencent's PR strategies while only $21.1 \%$ considered Qihoo's strategies poor. The same results could be applied to crisis communication and media application.

\section{Outcome of Focus Groups Interview}

The answers from the focus group also demonstrate that Qihoo gains more support from the public than Tencent. Comparing the strategies these two companies applied, the participants recognized that they have taken similar strategies while producing different effects. They admitted that they have been influenced, not only by the news release and public relations activities, but the opinions of the public. It can be concluded that some unmanageable factors, such as psychological elements, have subtle impact during the crisis.

\section{Outcome of Content Analysis}

Figure 1 suggests that, on average, before 26th July 2010, the publishing date of the article "Damn Tencent", media's attitude toward Tencent was better than that toward Qihoo. Among reports published between April 27th and July 26th, Tencent was identified as a successful company and had a supportive attitude. From April 27th to November 3rd, the media's attitude toward both Tencent and Qihoo fluctuated above and below "Neutral", though the conflict between them continually escalated during this period. In most cases, 
the battle between these two companies served as a farce to both media and the public. However, the publishing of Tencent's statement about taking drastic measures changed the status quo, since the statement forced users to make a choice between Qihoo's antivirus service software and Tencent's instant messaging software, involving the public's interest into their battle. On November 4th, most of the media directed their spearhead against Tencent for its attack on its competitor at the expense of users' interests. By contrast, Qihoo's posture of weakness helped regain the media's support.

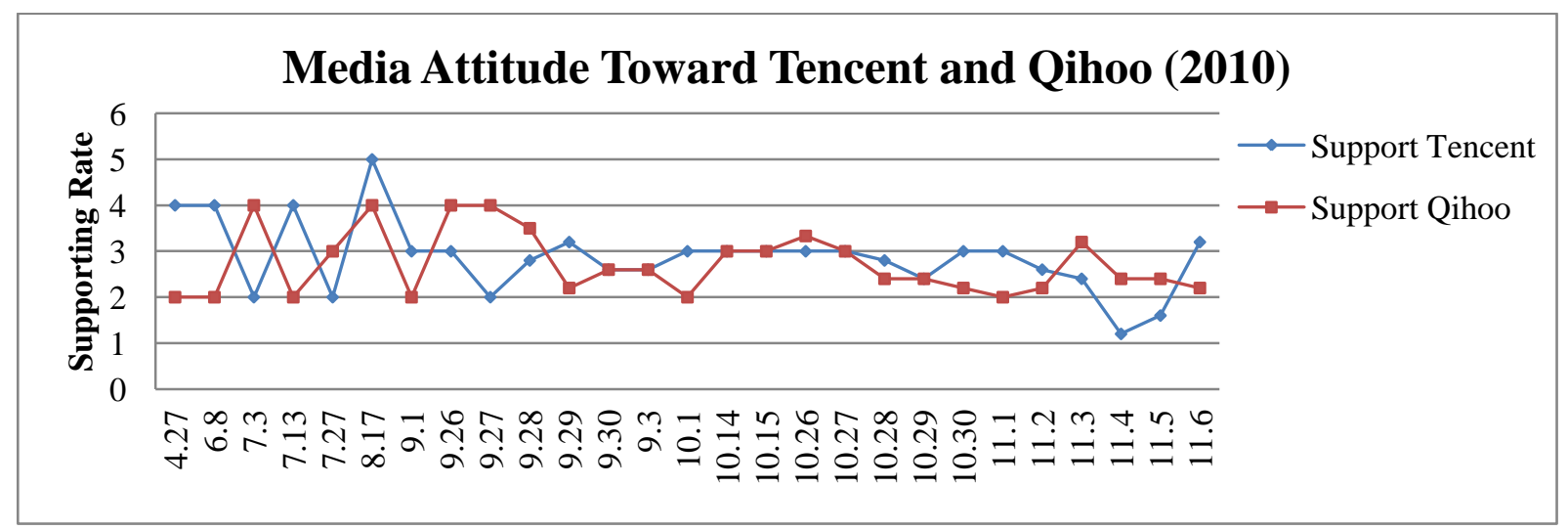

Figure 1 Content Analysis of Media Attitude toward Tencent and Qihoo

Figure 2 suggests that of Qihoo's support rate increased as the battle developed, while Tencent gradually lost its support. Qihoo's supporting rate peaked at the date of Tencent's decision on making its instant messaging software incompatible with the safety system Qihoo, with 60\% supporting Qihoo.

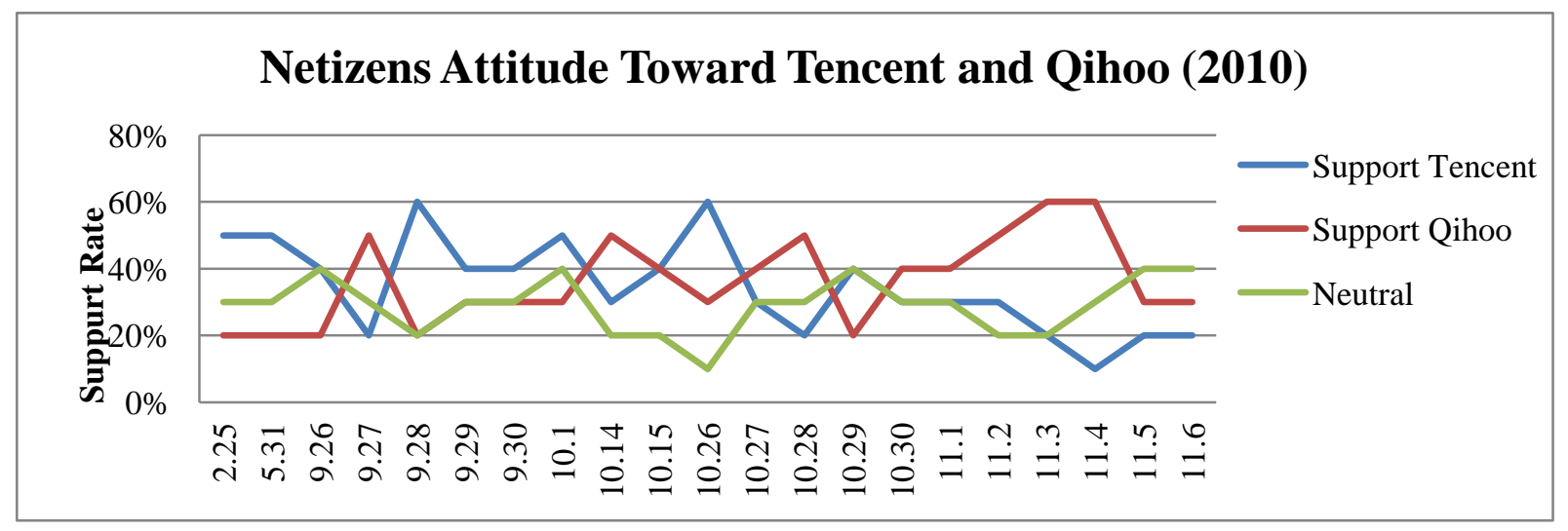

Figure 2 Content Analysis of Netizens Attitude toward Tencent and Qihoo 


\section{Analysis of the Outcomes}

It can be concluded from the outcomes that though the two companies have taken similar strategies, Qihoo was the winner compared to Tencent. From the perspective of public relations, Qihoo obtained a better corporate reputation than Tencent. Moreover, attitudes of the public changed as the crisis developed.

One third of the respondents to the questionnaire admitted that they had changed their minds during the crisis. Participants from the focus group also claimed that their opinions were driven by the public opinion. The media coverage analysis demonstrates a clear variation attitude from the beginning to the end. Some respondents of the survey who changed their attitudes during the crisis even stated that they took the absolutely opposite views from their original ones.

According to our research, the main factor affecting their attitude is the surrounding environments, including comments from the friends or/and the internet. This successfully illustrates the theory the Spiral of Silence. Individual opinions are greatly affected by the public attitudes because most people would like to follow the main trend or else be silent if they recognize that their opinions represent the minority. Different voices tend to be hidden in the general trend. Public opinion could reframe an individual's opinion and cause the attitude to be revised. During focus group interviews, most participants mentioned that there was lack of rationality when public dealt with the crisis, especially when Tencent took the drastic measures of making its instant messaging software incompatible with the safety system Qihoo. Since that turning point, the individual people assembled as a crowd and became sensitive and irrational when they perceived their own interests were involved and challenged in the crisis, which means crowd psychology exerted a subtle influence on public opinion. With the help of the spiral of silence for the formation of the crowd, the crowd psychology became an unmanageable factor in the "macro-public" environment and led to different results in crisis management.

\section{CONCLUSION AND DISCUSSION}

The battle between Tencent and Qihoo is a crucial part of China's Internet history, and this crisis is different from any other type of crisis defined before: it is the combination of the malevolence crisis, confrontation crisis, skewed value crisis and misconduct crisis. The most significant characteristic is the involvement of the public, and their behaviors and variation in this crisis, which makes this case quite different from any others. 
Tencent's 712 million users and Qihoo's 378 million users are much larger than most countries' populations, such an enormous population in the background of electronic environment, involved a new collective in the crisis which we called the "macro-public". The "Macro-public" is more likely to assemble and act as a crowd, especially in the electronic environment, like the netizens in this case: they connect their own opinion with the macro-public opinion according the spiral of silence, which is positive for them to form a crowd. Then they are a "macro-public" crowd with "Several of the special characteristics of crowds such as impulsivity, irritability, incapacity to reason, absence of judgment or critical spirit, exaggeration of emotions and more besides are also observed amidst lower forms of evolution such as the savage and the child (Le Bon, 1982, p.23)." Therefore, this scenario is a crisis involving the "macro-public's" interest, which we may call a "Macro-Public-Crisis", and, accordingly, this kind of crisis needs not only "Micro-public relations", but also "Macro-public relations".

Through these kinds of "Macro-public relations", netizens' attitudes and opinions varied throughout the crisis, more people supported Qihoo or were pro-Qihoo, affected by other people or mass media's opinion, this trend of variation fits into the spiral of silence. Particularly, this trend reached its peak when Tencent took drastic measures that made Tencent incompatible with Qihoo. At that moment, the users became impulsive and irrational, cursing Tencent, and became overwhelmingly pro-Qihoo. That fits with crowd psychology's impact on this new "macro-public" crowd.

Besides the theoretical implication of defining and highlighting the power and function of "macro-public relations" as crisis communication in the electronic backdrop, the study also intends to offer some of the following practical implications:

Firstly, companies, especially big companies with an enormous number of users or other stakeholders, must be aware that besides the "segmented-stakeholders" or "micro-public," their enormous stakeholders may also assemble and act as a "macro-public", especially when their interests are challenged and when the environment is fit to the formation of crowd.

Secondly, be aware that this "macro-public" may behave quite differently from that when they are individuals. They are impulsive, irritable and irrational; therefore, we should not do something wrong or evil to irritate them. To some extent, "Do Right Things" is much more important than "Do Things Right". 
Thirdly, besides the line of "Micro-public relations", "Macro-public relations" may be employed when companies face "Macro-Public-Crisis". In situations of "Macro-Public-Crisis", "Macro-public relations" is much more effective than "Micro-public relations". And there are some specific strategies or principles which different from that of "Micro-public relations", like the "KISS Principle" and "Affirmation-Repetition-Contagion Principle".

The "KISS principle" ("Keep It Simple, Stupid") is often applied in complex social systems like the crowd (Axelrod, 1997), which states that agent modeling should be simple even though the observed phenomenon is complex. This approach is mainly used in the analysis of the relationship between the macro properties of the entire system and the micro properties of the agents constituting the system (Epstein \& Axtell, 1996), and the same for a "Macro-Public-Crisis".

The "Affirmation-Repetition-Contagion Principle" is a principle that we can draw form Le Bon's crowd psychology: “Affirmation pure and simple, kept free of all reasoning and all proof, is one of the surest means of making an idea enter the mind of crowds.... Affirmation, however, has no real influence unless it is constantly repeated, and so far as possible in the same terms (Le Bon, 1982, p.72)." That action is somewhat slow, but it really works. And once it is produced, it is lasting and self-proliferating, like a contagion. Undoubtedly, this principle can serve in a "Macro-Public-Crisis".

\section{REFERENCES}

Allport, F.H. (1937). Toward a science of public opinion. Public Opinion Quarterly, 1(1), 7-23. http://dx.doi.org/10.1086/265034

Axelrod, R. (1997). The Complexity of Cooperation: Agent-Based Models of Competition and Collaboration. New Jersey: Princeton University Press.

Blumer, H. (1948). Public opinion and public opinion polling. American Sociological Review, 13(5), 542-555. http://dx.doi.org/10.2307/2087146

Cozier, Z.R., \& Witmer, D.F. (2001). The development of a structuration analysis of new publics in an electronic environment. In R.L. Heath (Ed.), Handbook of Public Relations (pp. 479-500). London: Sage.

Epstein, J.M., \& Axtell, R.L. (1996). Growing Artificial Societies: Social Science from the Bottom Up. Cambridge, MA: MIT Press.

Fearn-Banks, K. (1996). Crisis communication theory and ten businesses hit by news-making crisis. In S.G. Amin and S. Fullerton (Ed.), Global Business Trends 
(pp. 55-62). Cumberland, MD: Academy of Business Administration.

Fearn-Banks, K. (2001). Crisis communication: A review of some best practices. In R.L. Heath (Ed.), Handbook of Public Relations (pp. 479-500). London: Sage. http://dx.doi.org/10.4135/9781452220727.n40

Fink, S. (1986). Crisis Management: Planning for the Inevitable. New York: American Management Association.

Glynn, C.J., \& McLeod, J. (1985). Implications of the spiral of silence theory for communication and public opinion research. In K.R. Sanders, L.L. Kaid, and D. Nimmo (Eds.), Political Communication Yearbook, 1984 (pp. 43-65). Carbondale: Southern Illinois University Press.

Gordon, J.C. (1997). Interpreting definitions of public relations: Self-assessment and a symbolic-interactionism alternative. Public Relations Review, 23(1), 57-66. http://dx.doi.org/10.1016/S0363-8111(97)90006-0

Grunig, J.E., \& Grunig, L.A. (1992). Models of public relations and communications. In J.E. Grunig (Ed.), Excellence in Public Relations and Communication Management (pp. 285-326). Hillsdale, NJ: Lawrence Erlbaum.

Herbst, S. (1993). Numbered Voices. Chicago: University of Chicago Press.

Le Bon, G. (1982). The Crowd: A Study of the Popular Mind. Atlanta, GA: Cherokee (Original work published 1935).

Lippmann, W. (1922). Public Opinion. New York: Harcourt Brace Jovanovich.

McPhail, C. (1991). The Myth of the Madding Crowd. New York: Aldine de Gruyter.

Middleberg, D. (1996). How to avoid a cybercrisis. Public Relations Tactics, 3(11), 1-15.

Mitroff, I.I., \& Pearson, C. (1993). Crisis Management: A Diagnostic Guide for Improving Your Organization's Crisis Preparedness. San Francisco: Jossey-Bass.

Noelle-Neumann, E. (1974). The spiral of silence: A theory of public opinion. Journal of Communication, 24(2), 43-51. http://dx.doi.org/10.1111/j.1460-2466.1974.tb00367.x Price, V.E. (1992). Public Opinion. Newbury Park, CA: Sage.

Salmon, C.T., \& Kline, G. (1985). The spiral of silence ten years later: An examination and evaluation. In K.R. Sanders, L.L. Kaid, and D. Nimmo (Eds.), Political Communication Yearbook 1984 (pp. 3-30). Carbondale: Southern Illinois University Press.

Turner, R., \& Killian, L. (1987). Collective Behavior ( $3^{\text {rd }}$ ed.). Englewood Cliffs: Prentice-Hall.

Vasquez, G.M. \& Taylor, M. (2001). Research perspectives on 'the public'. In R.L. Heath 
International Journal of Cyber Society and Education 136

(Ed.), Handbook of Public Relations (pp. 139-154). London: Sage. http://dx.doi.org/10.4135/9781452220727.n10 


\section{APPENDIX}

\section{Appendix A: Questionnaire Survey Questions}

Response to the following questions range from 1="Totally disagree" to 5="Totally agree".

A1 Comparatively speaking, Tencent is the winner of the event.

A2 Comparatively speaking, Qihoo is the winner of the event.

A3 I had never changed my attitude during the event.

A4 I changed my attitude because of media reports.

A5 I changed my attitude because of friends' comments.

A6 I changed my attitude because of the Internet opinions.

A7 I appreciate Tencnet's PR strategies.

A8 I do not like Tencent's crisis response.

A9 I like Tencent's Media use.

A10 I appreciate Qihoo's PR strategies.

A11 I do not like Qihoo's crisis response.

A12 I like Qihoo's Media use.

A13 I recognize that people's attitude towards Tencent and Qihoo changed after Tencent's "tough decision".

\section{Appendix B: Focus Group Questions}

1. In the "Tencent vs. Qihoo" event, comparatively speaking, which company was the winner of the event, Tencent or Qihoo?

2. From the perspective of public relations, whose public relations strategies and activities were better?

3. Did the masses attitude and evaluation of the event change during the event?How did these changes occur? Did these changes have a trend route?

4. How would you evaluate these two companies' PR strategies and the corresponding results?

5. In these numerous PR strategies and techniques, how would you evaluate the "network warfare" of the companies? Or, in other words, how would you evaluate the impacts of the Internet, like microblogs, on the event?

6. Besides the PR strategies, were there any other factors that affected the development and change of the event (especially the change of the masses attitude)?

7. Was the masses attitude and evaluation of the event influenced by the media reports, or influenced by other people's views, especially when they aired their personal 
opinions of the event?

8. Was the masses performance some sort of "herd phenomenon"? How would you comment on Tencent's "tough decision"? Was the "tough decision" a flashpoint or a turning point of the whole event? Why?

9. Did the public's attitudes, reason and judgment, etc. changed after the "tough decision"? Or, was there a noticeable difference? More rational or more irrational? Higher or lower level of judgment? More one-sided attitude, more neutral or remained unchanged?

10. Why did these changes occur? Were there any special reasons? 